\title{
Antioxidant and Antibacterial Activities in the Leaf Extracts of Indian Borage (Plectranthus amboinicus)
}

\author{
Praveena Bhatt, Pradeep S. Negi \\ Human Resource Development, CSIR-Central Food Technological Research Institute (CFTRI), Mysore, India. \\ Email: psnegi@cftri.res.in
}

Received November $25^{\text {th }}, 2011$; revised December $26^{\text {th }}, 2011$; accepted January $4^{\text {th }}, 2012$

\begin{abstract}
The different solvent extracts of the leaves of Plectranthus amboinicus were evaluated for their antioxidant and antibacterial properties. The ethyl acetate extract of the leaves which had the highest polyphenolic content showed an appreciable DPPH radical scavenging activity as well as total antioxidant capacity as compared with extracts obtained using hexane, acetone, methanol, hydroalcohol and freeze dried form. The acetone extract of the leaves which had the second highest polyphenolic content showed appreciable antibacterial activity with least MIC values against the tested foodborne pathogens namely Staphylococcus aureus, Bacillus cereus, Escherichia coli and Yersinia enterocolitica. The findings indicated the potentiality of ethyl acetate and acetone extract of the leaves of Indian borage for use as biopreservatives as they showed high antioxidant and antibacterial activities.
\end{abstract}

Keywords: Total Phenolic Content; DPPH Radical Scavenging; Total Antioxidant Capacity; Antibacterial Activity; Plectranthus amboinicus

\section{Introduction}

Biochemical reactions in the body generate reactive oxygen species which can damage important bio-molecules, leading to several disease conditions. The harmful action of the free radicals can be blocked by antioxidants which scavenge the free radicals and nullify their damaging effect on cellular constituents. Natural antioxidants from plants have been shown to increase the antioxidant capacity of the plasma and reduce the risk of certain diseases such as cancer, heart diseases and stroke [1]. Dietary antioxidants can stimulate cellular defenses and help to prevent cellular components against oxidative damage. In addition they have been used in the food industry to prolong shelf life as they inhibit lipid oxidation. Majority of the antioxidants from plants are secondary metabolites like phenolics and flavonoids that have been reported to be potent free radical scavengers. They are found in different parts of the plants such as leaves, fruits, seeds, roots and bark [2]. Many of these phenolic compounds also possess other functional attributes like antimicrobial, anti-inflammatory, antimutagenic, hypocholestemic and antiplatelet aggregation properties.

Synthetic antioxidants and antimicrobials in use have been shown to have harmful side effects [3-5]; therefore, there is a need for more effective, less toxic and cost effective antioxidants and antimicrobials from natural sources. Several medicinal plants with ethno-botanical uses have been used traditionally in the treatment of diseases and have been exploited for these desired traits [6-8]. Consequently, there has been a growing interest to identify natural antioxidants and antimicrobials from these plants [9,10]. Plectranthus amboinicus [Lour.] Spreng, also known as Indian borage, is a medicinal plant, widely used in the Indian system of medicine. It belongs to the family Lamiaceae and is also called as country borage in English [11]. It is a large succulent aromatic perennial herb found throughout India, Moluccas and Ceylon [12, 13]. Many pharmacological properties have been reported in $P$. amboinicus including urolithiasis, antiepileptic, antitumorogenic, antimutagenic, radioprotective effect, antiviral, antifungal and neuropharmocological properties [14]. A decoction of its leaves is used in cases of chronic cough and asthma, and also as an antispasmodic, stomachic, and for the treatment of headache, fever, epilepsy and dyspepsia $[15,16]$. It is also used in the treatment of skin ulcerations and urinary diseases, as well as to alleviate inflammation, kidney troubles, nervous disorders and in conditions of congestive heart failure [17,18]. Ethanobotanical uses of $P$. amboinicus were recently reviewed by Lukhoba et al. [19].

Kumaran and Karunakaran [20] first reported the antioxidant and free radical scavenging activity of the aqueous extract of leaves of Indian borage. The leaf extract exhibited good antioxidant potency and showed 
significant reducing power, superoxide scavenging ability, nitric oxide scavenging and also ferrous ion chelating ability. However, Khanum et al. [21] observed less antioxidant activity in aqueous ethanolic extracts $(50 \%)$ of $P$. amboinicus leaves owing to lower extraction of total phenolics and total flavonoids in its ethanolic extract. Chandrappa et al. [22] used the ethanolic and hot water extract of the leaves of $P$. amboinicus and showed that it had antibacterial property against both Gram positive and Gram negative organisms. Also, the hydroalcoholic extract (HAE) of the leaves had antibacterial activity against methicillin resistant Staphylococcus aureus [23]. The anti-mutagenic, antitumorogenic and antigenotoxic effect of the leaves was demonstrated by Annapurani and Priya [24] in their experiments using the HAE extract.

In the background of research studies undertaken with P. amboinicus extracts till date, in the present study an attempt was made to evaluate the antioxidant and antibacterial potency of various solvent extracts of the leaves. A comparison was also made with HAE of the leaves as it is one of the most studied P. amboinicus extract available in the literature.

\section{Materials and Methods}

\subsection{Plant Material and Chemicals}

The leaves of $P$. amboinicus were collected from the campus of Central Food Technological Research Institute (CFTRI), Mysore, India. The plant material was identified by Mr. A. S. Chauhan, Scientist, Fruit and Vegetable Technology Department, CFTRI, Mysore, and a specimen voucher was deposited in the Fruit and Vegetable Technology Departmental Herbarium (FVT DH No. LGMGHCC-PA-8/2011). All the solvents and chemicals used were of AR grade (Qualigen, India).

\subsection{Methods}

\subsubsection{Extraction}

The leaves of $P$. amboinicus were washed in running tap water and dried at low temperature $\left(55^{\circ} \mathrm{C}\right)$ in hot air oven (Industrial and Laboratory Instrument Corporation, Chennai, India). The dried leaves were powdered using a mixer grinder (Johnson, Mumbai, India) and used for sequential extraction with hexane, ethyl acetate, acetone and methanol based on their polarity in order to obtain antioxidant and antibacterial rich fractions. The dried leaves $(50 \mathrm{~g})$ were mixed with the first solvent in the series (hexane, $500 \mathrm{ml}$ ) and placed on a magnetic stirrer with stirring for $24 \mathrm{hr}$ at $30^{\circ} \mathrm{C}$. The extract was filtered using Whatman filter No. 41 to obtain a particle free extract. The leaves were re-extracted with the solvent three times, filtered and the extract was pooled. The next solvent (ethyl acetate, $500 \mathrm{ml}$ ) was added to the residual leaves (free of the previous solvent) and the above procedure was followed to obtain other solvent extracts. The same procedure was repeated with acetone and methanol. All the solvent extracts were concentrated by evaporation of solvent at ambient temperature in a fume hood and extracts were made solvent free by final drying under vaccum $\left(25 \mathrm{~mm} \mathrm{Hg}\right.$ at $\left.40^{\circ} \mathrm{C}\right)$.

For the purpose of comparison, hydroalcoholic (HAE) and freeze dried (FD) extracts were also included. The HAE extract was prepared by grinding fresh leaves in a mixer with a mixture of alcohol and water (80:20). The leaves were left overnight with shaking in a magnetic stirrer unit for $24 \mathrm{hr}$. The extract was filtered using Whatman paper No. 41 to obtain a particle free filtrate. The residual leaves were again extracted twice with the alcohol water mixture. The extract was pooled, concentrated using a flash evaporator (Buchi Rotavapor-R, Switzerland) and made solvent free by final drying under vaccum $\left(25 \mathrm{~mm} \mathrm{Hg}\right.$ at $\left.40^{\circ} \mathrm{C}\right)$. The freeze dried extract of $P$. amboinicus was prepared by the method given by $\mathrm{Ku}-$ maran and Karunakaran [20]. Briefly, fresh leaves were washed three times with tap water, ground in a mixer grinder and the slurry was extracted with distilled water (1:5) for $1 \mathrm{~h}$ at $90^{\circ} \mathrm{C}$. The supernatant was filtered through Whatman No. 1 filter, concentrated using a flash evaporator and the resultant extract was lyophilized in a lyophilizer (Heto, Model Ce/DW 60E, Denmark).

For use in antioxidant assays, the aliquots of the solvent free extracts $(1000 \mu \mathrm{g} / \mathrm{ml})$ were prepared in acetone for non-polar extracts (hexane, ethyl acetate) and methanol for polar extracts (acetone, methanol), HAE and freeze dried extract, whereas all the extracts were dissolved in propylene glycol (PG) for use in the antibacterial experiments.

\subsubsection{Estimation of Total Phenolics}

The concentration of phenolics in the extracts was determined by a method given by Singleton \& Rossi [25] with modifications. Different concentrations of extracts were mixed with $1.0 \mathrm{ml}$ of 10 fold diluted Folin-ciocalteu reagent and $1 \mathrm{ml}$ of saturated sodium carbonate solution. After allowing it to stand for $30 \mathrm{~min}$ at $30^{\circ} \mathrm{C}$, the absorbance was measured at $765 \mathrm{~nm}$ using a UV-visible spectrophotometer (Shimadzu, Japan). Total phenolics were calculated using a standard gallic acid curve and results were expressed as mg gallic acid equivalent/g of extract.

\subsubsection{Evaluation of Antioxidant Potential of Extracts}

\subsubsection{DPPH Radical Scavenging Assay}

The free radical scavenging activity of the extract was measured in vitro by 1,1-diphenyl-2-picrylhydrazyl (DPPH) assay [26]. Various concentration of the extracts adjusted in a final volume of $2.5 \mathrm{ml}$ were mixed with $5 \mathrm{ml}$ of 0.1 $\mathrm{mM}$ DPPH solution. The tubes were shaken properly and 
incubated for $20 \mathrm{~min}$ in the dark. The changes in the absorbance of the samples were measured at $517 \mathrm{~nm}$ using a spectrophotometer. The radical scavenging activity of the extracts at different concentrations was determined and compared with that of butyl hydroxy anisole (BHA), which was used as the standard. DPPH solution without extract/standard formed the control. The DPPH radical scavenging activity was given as

$$
\% \text { DPPH radical scavenging }=100 \times\left(A_{0}-A_{s}\right) / A_{0}
$$

where $A_{0}$ is absorbance of control and $A_{s}$ is absorbance of sample. All samples were run in triplicate and radical scavenging activity was reported as mean $\pm \mathrm{SD}$.

\subsubsection{Total Antioxidant Capacity}

The total antioxidant capacity of various extracts was evaluated using the phosphomolybdenum method of Prieto et al. [27] with slight modification. Extracts $(300 \mu \mathrm{g})$ were dissolved in a mixture of $3 \mathrm{ml}$ of reagent solution (0.6 M sulphuric acid, $28 \mathrm{mM}$ sodium phosphate and 4 $\mathrm{mM}$ ammonium molybdate) and incubated at $95^{\circ} \mathrm{C}$ for 90 min. After the samples were cooled to ambient temperature, the absorbance of the solution was measured at 695 $\mathrm{nm}$ against reagent blank containing only the respective solvents. The results were reported as $\mu \mathrm{M}$ ascorbic acid equivalents/g of extract.

\subsubsection{Antibacterial Potential of the Extracts}

The leaf extracts of $P$. amboinicus were tested against Bacillus cereus, Staphylococcus aureus, Escherichia coli and Yersinia enterocolitica by the method of Negi et al. [28]. One hundred $\mu \mathrm{l}$ of overnight grown bacterium diluted to $10^{3} \mathrm{cfu} / \mathrm{ml}$ was inoculated into the flask containing $20 \mathrm{ml}$ nutrient agar and different concentrations of leaf extracts, and the contents were poured into sterilized petri plates. The plates were observed for bacterial growth after overnight incubation at $37^{\circ} \mathrm{C}$ and minimum inhibitory concentration (MIC) was defined as the lowest concentration of the compound capable of inhibiting the complete growth of bacteria.

\subsubsection{Statistical Analysis}

The results obtained in various experiments were expressed as mean $\pm \mathrm{SD}(\mathrm{n}=3)$. All the extracts were compared with HAE using the t-test in microsoft excel and significance was determined at 5\% level. The correlation coefficient for TPC and the DPPH scavenging activity of the extracts was also calculated using Microsoft Excel.

\section{Results and Discussion}

The leaves of $P$. amboinicus were extracted by three different methods viz. sequential, hydroalcoholic (HAE) and freeze dried (FD) form, in order to select the most potent antioxidant and antibacterial fraction. The highest yield was obtained with sequential methanolic extract $(8.75 \%)$, while the lowest was that for acetone $(0.59 \%)$. The yield of various extracts was in the order of methanol $(8.75 \%)>$ ethyl acetate $(6.98 \%)>$ FD $(3.56 \%)>$ hexane $(3.5 \%)>\operatorname{HAE}(1.43 \%)>$ acetone $(0.59 \%)$.

The total phenolic content in the different extracts showed that ethyl acetate and acetone extracts had significantly $(\mathrm{p} \leq 0.05)$ higher total phenolics than HAE, whereas FD, methanol, and hexane extracts had significantly $(\mathrm{p} \leq 0.05)$ lower total phenolics than HAE (Figure 1). In general, it is reported that extraction of phenolic compounds is highest when methanol or aqueous methanol is used [29,30]. However, a slightly higher TPC in acetone extract as compared to methanolic extract of pomegranate rinds has been reported previously [31]. Probably, due to sequential extraction procedure, where methanol is used after ethyl acetate and acetone a lower TPC in methanol was obtained in the present study. Ethyl acetate has a concentrating effect on plant phenolics [32]. Alisi and Onyeze [33] also showed that the ethyl acetate fraction of the leaves of Chromoraena odorata contained $31 \%$ more phenolics than the methanolic extract similar to what was observed in our study.

The DPPH radical is a widely used model to evaluate the antioxidant property of plant extracts [34]. DPPH is a stable nitrogen-centered free radical, the color of whichchanges from violet to yellow upon reduction by either the process of hydrogen- or electron-donation. Substances which are able to perform this reaction can be considered as antioxidants and therefore radical scavengers [35]. The radical scavenging activity of the extracts of $P$. amboinicus at different concentrations is shown in Table 1. Results show that at $100 \mathrm{ppm}$, the radical scavenging activity was highest for ethyl acetate extract $(54.18 \%)$, while it was least for hexane extract $(11.8 \%)$. The scavenging activity of the extracts was dose de

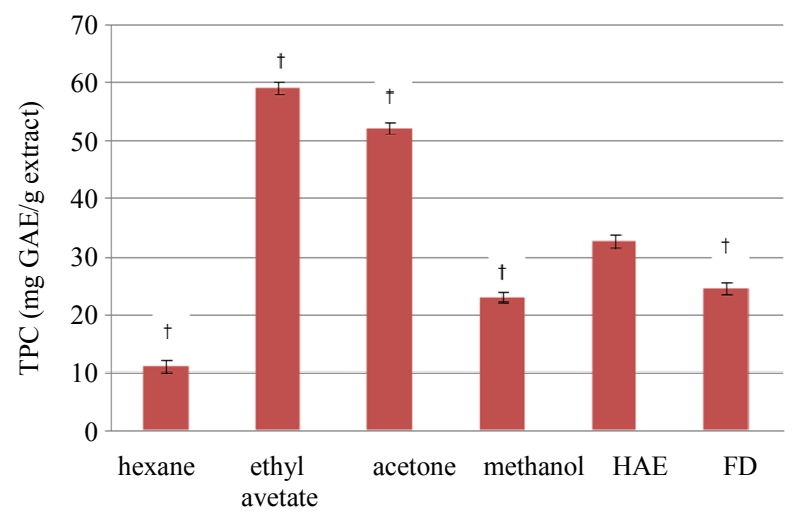

Figure 1. Total phenolic content (TPC) of the different solvent extracts of $P$. amboinicus. ${ }^{\dagger}$ Values were significantly (p $\leq \mathbf{0 . 0 5}$ ) different as compared to HAE. 
Table 1. DPPH radical scavenging activity of different extracts of $P$. amboinicus leaves.

\begin{tabular}{|c|c|c|c|c|c|c|c|}
\hline \multirow{3}{*}{ Concentration (ppm) } & \multicolumn{7}{|c|}{ \% DPPH radical scavenging activity } \\
\hline & \multirow[t]{2}{*}{ BHA } & \multicolumn{4}{|c|}{ Sequential } & \multirow[t]{2}{*}{ HAE } & \multirow[t]{2}{*}{ FD } \\
\hline & & Hexane & Ethyl acetate & Acetone & Methanol & & \\
\hline 20 & $95.82 \pm 0.1$ & $7.18 \pm 0.38$ & $26.88 \pm 0.6$ & $23.6 \pm 1.22^{\dagger}$ & $13.13 \pm 0.42$ & $21.58 \pm 0.79$ & $15.67 \pm 2.30$ \\
\hline 40 & $95.87 \pm 0.1$ & $8.92 \pm 0.05$ & $32.84 \pm 1.48$ & $30.8 \pm 3.03^{\dagger}$ & $13.49 \pm 0.40$ & $23.64 \pm 2.61$ & $20.45 \pm 1.6^{\dagger}$ \\
\hline 60 & $96.20 \pm 0.2$ & $9.56 \pm 0.68$ & $41.83 \pm 1.26$ & $42.6 \pm 3.67$ & $14.79 \pm 0.17$ & $24.20 \pm 0.45$ & $22.80 \pm 0.3^{\dagger}$ \\
\hline 80 & $96.20 \pm 0.1$ & $10.65 \pm 0.5$ & $48.23 \pm 0.81$ & $46.1 \pm 1.97$ & $15.32 \pm 0.11$ & $26.35 \pm 1.25$ & $23.82 \pm 0.98$ \\
\hline 100 & $96.20 \pm 0.1$ & $11.8 \pm 0.16$ & $54.18 \pm 0.5$ & $50.2 \pm 1.99$ & $19.40 \pm 0.20$ & $27.62 \pm 1.67$ & $24.44 \pm 0.78$ \\
\hline
\end{tabular}

$\dagger$ Values were statistically similar $(\mathrm{p} \leq 0.05)$ to HAE at respective concentration.

pendant. The DPPH radical scavenging activity of the plant extracts was in the order of ethyl acetate $>$ acetone $>$ HAE $>$ FD $>$ methanol $>$ hexane. The DPPH scavenging activity of the HAE in the present study was $27.62 \%$ at $100 \mathrm{ppm}$, which was at par with the DPPH scavenging activity of the $50 \%$ ethanolic extract of Indian borage leaves (30.4\%) at similar concentration [22]. In our experiments, it was observed that the radical scavenging activity in the plant extracts correlated well (correlation coefficient $=0.98$ ) with the data obtained for the total phenolic content in them. This observation has also been reported by other researchers $[25,36,37]$.

Phenolic compounds in plant extracts contribute significantly to their antioxidant potential because of their unique structure. Phenolics are composed of one (or more) aromatic rings bearing single or multiple hydroxyl groups and are therefore potentially able to quench free radicals by forming resonance-stabilized phenoxyl radical $[38,39]$. The percent inhibition of DPPH radical by the extracts was compared to a synthetic antioxidant namely butylated hydroxyanisole (BHA). All the fractions showed less radical scavenging activity compared to BHA. The activity of the extract which showed the highest DPPH radical scavenging activity (ethyl acetate) was approximately half of BHA at $100 \mathrm{ppm}$ concentration. At around $200 \mathrm{ppm}$, the ethyl acetate fraction shows nearly $93 \%$ DPPH scavenging activity (data not shown). Although, when compared to BHA, the concentration required for an equivalent activity was higher for this fraction, there is widespread agreement that synthetic oxidants like BHA and butylated hydroxytoluene (BHT) need to be replaced with natural antioxidants considering their potential health risks and toxicity [40].

The total antioxidant capacity of the plant extracts was determined by the phosphomolybdenum method. This method is based on the reduction of molybdenum Mo (VI) to Mo (V) by the antioxidant compounds and the formation of a green Mo (V)-antioxidant complex with maximum absorption at $695 \mathrm{~nm}$. The results of the total antioxidant capacity of the leaf extract of $P$. amboinicus are presented in Table 2

The total antioxidant activity was highest in the ethyl acetate extract $(3085.8 \pm 2.53 \mu \mathrm{M} \mathrm{AAE} / \mathrm{g}$ extract) followed by acetone $>$ methanol $>$ HAE $>$ FD. However, this result does not correlate very well with the sequence obtained for the DPPH radical scavenging activity, wherein activity of the methanolic extract was less as compared to the HAE and FD fraction.

Antibacterial activity of the different extracts was evaluated by agar dilution method against four foodborne pathogens and expressed in terms of minimum inhibitory concentration (MIC in ppm). The MIC of extracts against different pathogens varied depending on pathogen and extract in question (Table 3). Among the pathogens tested, $B$. cereus was the most sensitive species and showed the least MIC value. Hexane and freeze dried extracts could not inhibit the complete growth of B. cereus even at $2500 \mathrm{ppm}$ concentration, and were therefore not tested against other pathogens. Among all the extracts, acetone extract showed lowest MIC values against the tested cultures. The antibacterial activity may be attributed to the phenolic content. The antibacterial activity of ethyl acetate extract was higher than methanol and HAE extract as it had the highest phenolics. Although, acetone extract had lower phenolics than ethyl acetate

Table 2. Total antioxidant capacity (TAC) of different leaf extracts of $P$. amboinicus.

\begin{tabular}{ccc}
\hline \multicolumn{2}{c}{ Extracts } & $\begin{array}{c}\text { TAC }(\mu \mathrm{M} \text { Ascorbic Acid Equivalent/g } \\
\text { of extract })\end{array}$ \\
\hline \multirow{3}{*}{ Sequential } & Hexane & $112.01 \pm 0.99^{\dagger}$ \\
Ethyl & acetate & $3085.8 \pm 2.53^{\dagger}$ \\
& Acetone & $3022.55 \pm 0.18^{\dagger}$ \\
Methanol & $782.56 \pm 1.21^{\dagger}$ \\
HAE & $523.57 \pm 3.60$ \\
FD & $474.06 \pm 2.91^{\dagger}$ \\
\hline
\end{tabular}

$\dagger$ Values were significantly $(\mathrm{p} \leq 0.05)$ different as compare to HAE. 
Table 3. Antibacterial activity of Indian borage extracts (MIC in ppm).

\begin{tabular}{|c|c|c|c|c|c|}
\hline \multicolumn{2}{|c|}{ Extract } & S. aureus & B. cereus & E. coli & Y. eterocolitica \\
\hline \multirow{4}{*}{ SEQUENTIAL } & Hexane & ND & $>2500$ & ND & ND \\
\hline & Ethyl acetate & 1250 & 1000 & 1000 & 1250 \\
\hline & Acetone & 750 & 437.5 & 1000 & 1000 \\
\hline & Methanol & 3750 & 2500 & 5000 & 3750 \\
\hline \multicolumn{2}{|c|}{ HAE } & 2500 & 1875 & 5000 & 2500 \\
\hline \multicolumn{2}{|c|}{ FD } & ND & $>2500$ & ND & ND \\
\hline
\end{tabular}

Values are result of four experiments where no growth was observed. ND: not determined.

extract, it showed better antibacterial activity than ethyl acetate extract. It has been reported, that not only total content, but the type of phenolics and their relative distribution is important for biological activity. Both acetone and ethyl acetate extract have higher phenolics and showed higher antioxidant and antibacterial activity than other extracts. Earlier works have reported antimicrobial activity of volatile oils of Plectranthus aromaticus against Gram positive and Gram-negative bacteria and fungi [41, 42]. Carvacrol, thymol, $\beta$-caryophyllene have been reported to be the active constituents of the essential oil of this plant [43-45]. However, in the present investigation we have tested the bioactivity of the non-volatile compounds present in various extracts, and higher amount of these compounds (probably phenolics) in the ethyl acetate and acetone extract of the leaves may be responsible for their higher bioactivity. In general, Gram-negative bacteria are more resistant than Gram-positive bacteria [29,46-51] and in the present study also Gram-negative bacteria showed higher MIC values for all the extracts. Higher resistance of Gram-negative bacteria than Grampositive bacteria against different antibacterial compounds is attributed to differences in their cell wall $[52,53]$ and outer membrane [54,55].

In summary, the present study showed that the biologically active constituents from $P$. ambonicus can be extracted with different solvents. The ethyl acetate extract in the present study showed higher phenolics and higher antioxidant activity. The acetone extract also showed highest antibacterial activity and good antioxidant activity. High antioxidant and antibacterial activities observed in acetone and ethyl acetate extracts does provide opportunities to explore them as biopreservatives.

\section{Acknowledgements}

The authors wish to express sincere thanks to Director, CFTRI and Head, Human Resource Development, CFTRI for constant encouragement. Authors also thank Mr. A. S. Chauhan, Principal Scientist, Fruit and Vegetable Technology Department, CFTRI, Mysore for identification of plant material.

\section{REFERENCES}

[1] R. L. Prior and G. Cao, "Antioxidant Phytochemicals in Fruits and Vegetables: Diet and Health Implications," Horticulture Science, Vol. 35, No. 4, 2000, pp. 588-592.

[2] S. Mathew and T. E. Abraham, "In Vitro Antioxidant Activity and Scavenging Effects of Cinnamomum verum Leaf Extract Assayed by Different Methodologies," Food Chemistry and Toxicology, Vol. 44, No. 2, 2006, pp. 198206. doi:10.1016/j.fct.2005.06.013

[3] J. J. Gao, K. Igalashi and M. Nukina, "Radical Scavenging Activity of Phenylpropanoid Glycosides in Caryopteris incana," Bioscience, Biotechnology and Biochemistry, Vol. 63, No. 6, 1999, pp. 983-988. doi:10.1271/bbb.63.983

[4] G. M. Williams, M. J. Iatropoulos and J. Whysner, "Safety Assessment of Butylated Hydroxyanisole and Butylated Hydroxyltoluene as Antioxidant Food Additives," Food Chemistry and Toxicology, Vol. 37, 1999, pp. 10271038. doi:10.1016/S0278-6915(99)00085-X

[5] T. Osawa, and M. Namiki, "A Novel Type of Antioxidant Isolated from Leaf Wax of Eucalyptus Leaves," Agriculture Biology and Chemistry, Vol. 45, No. 3, 1981, pp. 735-739. doi:10.1271/bbb1961.45.735

[6] V. R. Patel, P. R. Patel and S. S. Kajal, "Antioxidant Activity of Some Selected Medicinal Plants in Western Region of India," Advances in Biological Research, Vol. 4, No. 1, 2010, pp. 23-26.

[7] I. O. Okoro, A. Osagie and E. O. Asibor, "Antioxidant and Antimicrobial Activities of Polyphenols from Ethanomedicinal Plants from Nigeria," African Journal of Biotechnology, Vol. 20, 2010, pp. 2989-2993.

[8] L. Lagnika, E. Anago and A. Sanni, "Screening of Antibacterial, Antioxidant Activity and Toxicity of Some Medicinal Plants Used in Benin Folkloric Medicine," Journal of Medicinal Plant Research, Vol. 5, No. 5, 2011, pp. 773-777.

[9] C. A. Rice-Evans, "Flavonoids and Isoflavones: Absorption, Metabolism and Bioactivity," Free Radical Biology and Medicine, Vol. 36, No. 7, 2004, pp. 827-828.

[10] S. Chanda and R. Dave, "In Vitro Models for Antioxidant 
Activity Evaluation and Some Medicinal Plants Possessing Antioxidant Properties-An Overview," African Journal of Microbiology Research, Vol. 3, No. 13, 2009, pp. 981-996. doi:10.1016/j.freeradbiomed.2003.12.012

[11] K. R. Kirtikar and B. D. Basu, "Indian Medicinal Plants," Vol. 3, International Book Distributors, Dehradun, 1999, pp. 1970-1971.

[12] P. K. Warrier and V. P. Nambier, "Indian Medicinal Plants: A Compendium of 500 Species," Vol. 4, Orient Longman Ltd., Chennai, 1996, p. 315.

[13] Nadkarni, "Indian Materia Medica," 3rd Edition, Popular Prakashan, Mumbai, 2002, pp. 371-372.

[14] R. Patel, N. K. Mahobia, R. Ghendle, B. Kaushik and S. K. Singh, "Diuretic Activity of Leaves of Plectranthus amboinicus (Lour) Spreng in Male Albino Rats," Pharmocology Research, Vol. 2, No. 2, 2010, pp. 86-88.

[15] N. R. Khory and N. N. Katrak, "Materia Medica of India and Their Therapeutics," BDH Printers, New Delhi, 1999, p. 380

[16] J. F. Morton, "Country Borage (Coleus aromaticus Lour.): A Potent Flavouring and Medicinal Plant," Journal of Herbs, Spices and Medicinal Plants, Vol. 1, No. 1-2, 1992, p. 77. doi:10.1300/J044v01n01_09

[17] F. Franca, E. L. Lago and P. D. Marsden, "Plants Used in the Treatment of Leishmanial Ulcers Due to Leishmania (Viannia) braziliensis in an Endemic Area of Bahia, Brazil," Revista-Sociedade Brasileira de Medicinal Tropical, Vol. 29, No. 3, 1996, pp. 229-232.

[18] S. K. Jain and S. Lata, "Amazonian Uses of Some Plants Growing in India," Indigenous Knowledge and Development Monitor, Vol. 4, No. 3, 1996, pp. 21-23.

[19] C. W. Lukhoba, M. S. J. Simmonds and A. J. Paton, "Plectranthus: A Review of Ethanobotanical Uses," Journal of Ethanopharmcology, Vol. 103, No. 1, 2006, pp. 1- 24.

[20] A. Kumaran and R. J. Karunakaran, “Antioxidant and Free Radical Scavenging Activity of an Aqueous Extract of Coleus aromaticus," Food Chemistry, Vol. 97, No. 1, 2006, pp. 109-114. doi:10.1016/j.foodchem.2005.03.032

[21] H. Khanum, K. Ramalakshmi, P. Srinivas and B. B. Borse, "Synergistic Antioxidant Action of Oregano, Ajowan and Borage Extracts," Food and Nutrition Science, Vol. 2, No. 5, 2011, pp. 387-392. doi:10.4236/fns.2011.25054

[22] M. S. Chandrappa, R. Harsha, R. Dinesha and T. S. S. Gowda, "Antibacterial Activity of Coleus aromaticus Leaves," International Journal of Pharmacy and Pharmaceutical Sciences, Vol. 2, 2010, pp. 63-66.

[23] A. P. A. D. Gurgel, J. G. daSilva, A. R. S. Grangeiro, H. S. Xavier, R. A. G. Oliviera, M. S. V. Pereira and I. A. de Souza, "Antibacterial Affects of Plectranthus amboinicus [Lour.] Spreng (Lamiaceae) in Methicillin Resistant Staphylococcus aureus (MRSA)," Latin American Journal of Pharmacy, Vol. 28, No. 3, 2009, pp. 460-464.

[24] S. Annapurani and R. Priya, "Antimutagenic, Antitumorogenic and Antigenotxic Effects of Polyphenol Extracts of Selected Medicinal Plants," The Indian Journal of Nutrition and Dietetics, Vol. 36, 1999, pp. 431-435.

[25] V. L. Singleton and J. A. Rossi, "Colorimetry of Total
Phenolics with Phosphomolybdic-Phosphotungstic Acid Reagents," American Journal of Enology and Viticulture, Vol. 16, No. 3, 1965, pp. 144-158.

[26] M. S. Blois, "Antioxidant Determinations by the Use of a Stable Free Radical," Nature, Vol. 181, No. 4617, 1958, pp. 1199-1200. doi:10.1038/1811199a0

[27] P. Prieto, M. Pineda and M. Aguilar, "Spectrophotometric Quantitation of Antioxidant Capacity through the Formation of Phosphomolybdenum Complex: Specific Application for the Determination of Vit E," Analytical Biochemistry, Vol. 269, No. 2, 1999, pp. 337-341. doi:10.1006/abio.1999.4019

[28] P. S. Negi, G. K. Jayaprakasha, L. Jagan Mohan Rao and K. K. Sakariah, "Antibacterial Activity of Turmeric OilA By-Product from Curcumin Manufacture," Journal of Agricultural Food Chemistry, Vol. 47, No. 10, 1999, pp. 2397-2400. doi:10.1021/jf990308d

[29] M. Antolovich, P. Prenzler, K. Robards and D. Ryan, "Sample Preparation in the Analysis of Phenolic Compounds in Fruits," Analyst, Vol. 125, 2000, pp. 989-1009. doi:10.1039/b000080i

[30] P. S. Negi, A. S. Chauhan, G. A. Sadia, Y. S. Rohinishree and R. S. Ramteke, "Antioxidant and Antibacterial Activities of Various Seabuckthorn (Hippophae rhamnoides L.) Seed Extracts," Food Chemistry, Vol. 92, No. 1, 2005, pp. 119-124. doi:10.1016/j.foodchem.2004.07.009

[31] P. S. Negi, G. K. Jayaprakasha and B. S. Jena, "Antioxidant and Antimutagenic Activities of Pomegranate Peel Extract," Food Chemistry, Vol. 80, No. 3, 2003, pp. 393-397. doi:10.1016/S0308-8146(02)00279-0

[32] Y. Gow-Chin, L. His-Huai and C. Hsin-Yi, "Nitric Oxide Scavenging and Antioxidant Effects of Uraria crinitia Root," Food Chemistry, Vol. 74, No. 4, 2001, pp. 471478. doi:10.1016/S0308-8146(01)00165-0

[33] C. S. Alisi and G. O. C. Onyeze, "Nitric Oxide Scavenging Ability of Ethyl Acetate Fraction of Methanolic Leaf Extracts of Chromlaena odorata (Linn)," African Journal of Biochemistry Research, Vol. 2, No. 7, 2008, pp. 145150.

[34] M. A. Ebrahimzadeh, F. Pourmorad and S. Hafezi, "Antioxidant Activities of Iranian Corn Silk," Turkish Journal of Biology, Vol. 32, No. 1, 2008, pp. 43-49. doi:10.3989/gya.010109

[35] A. A. Dehpour, M. A. Ebrahimzadeh, S. F. Nabavi and S. M. Nabavi, "Antioxidant Activity of Methanol Extract of Ferula assafoetida and Its Essential Oil Composition," Grasas Aceites, Vol. 60, No. 4, 2009, pp. 405-412.

[36] N. Deighton, R. Brennan, C. Finn and H. V. Davies, "Antioxidant Properties of Domesticated and Wild Rubus Species," Journal of the Science of Food and Agriculture, Vol. 80, No. 9, 2000, pp. 1307-1313. doi:10.1002/1097-0010(200007)80:9<1307::AID-JSFA63 8>3.0.CO;2-P

[37] S. Dudonne, X. Vitrac, P. Coutiere, M. Woillez and J.-M. Merillon, "Comparative Study of Antioxidant Properties and Total Phenolic Content of 30 Plant Extracts of Industrial Interest Using DPPH, ABTS, FRAP, SOD, and ORAC Assays," Journal of Agricultural Food Chemistry, 
Vol. 57, No. 5, 2009, pp. 1768-1774. doi:10.1021/jf803011r

[38] C. A. Rice-Evans, N. J. Miller and G. Paganga, "Structure-Antioxidant Activity Relationships of Flavonoids and Phenolic Acid," Free Radical Biology and Medicine, Vol. 20, No. 7, 1996, pp. 933-956. doi:10.1016/0891-5849(95)02227-9

[39] W. Bors and C. Michel, "Chemistry of the Antioxidant Effect of Polyphenols," Annals of the New York Acadamy of Sciences, Vol. 957, 2002, pp. 57-69. doi:10.1111/j.1749-6632.2002.tb02905.x

[40] R. Kahl and H. Kappus, "Toxicology of the Synthetic Antioxidants BHA and BHT in Comparison with the Natural Antioxidant Vitamin E," Zeitschrift für Lebensmitteluntersuchung und-Forschung A, Vol. 196, No. 4, 1993, pp. 329-338. doi:10.1007/BF01197931

[41] G. S. J. G. Alankarrao, P. Baby and R. Y. Prasad, "Leaf Oil of Coleus amboinicus Lour: The in Vitro Antimicrobial Studies," Perfume and Kosmetik, Vol. 72, 1991, pp. 744-745.

[42] C. O. Samuel, L. J. Srivastava and S. C. Tripathi, "Protection of Dry-Fruits from Fungal Infestation by Essential Oil of Coleus amboinicus," Indian Journal of Plant Protection, Vol. 23, No. 2, 1995, pp. 174-179.

[43] R. Bos, H. Hendriks and F. H. van Os, "The Composition of the Essential Oil in the Leaves of Coleus aromaticus Bentham and Their Importance as a Component of the Species Antiaphthosae Ph. Ned. Ed. V," Pharmacy World \& Science, Vol. 5, No. 4, 1983, pp. 129-130. doi:10.1007/BF01961467

[44] S. Dutta, "Essential Oil of Coleus aromaticus of Indian Origin," Indian Oil and Soap Journal, Vol. 25, 1959, pp 120.

[45] G. R. Mallavarapu, L. Rao and R. Srinivasaiyer, "Essential Oil of Coleus aromaticus from India," Journal of Essentuial Oil Research, Vol. 11, 1999, pp. 742-744.

[46] R. Naganawa, N. Iwata, K. Ishikawa, H. Fukuda, T. Fujino and A. Sujuki, "Inhibition of Microbial Growth by Azoene, a Sulfur-Containing Compound Derived from Garlic," Applied Environmental Microbiology, Vol. 62, No.
11, 1996, pp. 4238-4242.

[47] A. Nastro, M. P. Germano, V. D’Angelo, A. Marino and M. A. Cannatelli, "Extraction Methods and Bioautography for Evaluation of Medicinal Plant Antimicrobial Activity," Letters in Applied Microbiology, Vol. 30, No. 5, 2000, pp. 379-384. doi:10.1046/j.1472-765x.2000.00731.x

[48] A. Brantner, Z. Males, S. Pepeljnjak and A. Antolic, "Antimicrobial Activity of Paliurus spina-christi Mill," Journal of Ethnopharmacology, Vol. 52, No. 2, 1996, pp. 119122. doi:10.1016/0378-8741(96)01408-0

[49] T. Ojala, S. Remes, P. Hansuu, H. Vuorela, R. Hiltunen, K. Haahtela and P. Vuorela, "Antimicrobial Activity of Some Coumarin Containing Herbal Plant Growing in Finland," Journal of Ethnopharmacology, Vol. 73, No. 1-2, 2000, pp. 299-305. doi:10.1016/S0378-8741(00)00279-8

[50] P. S Negi and G. K. Jayaprakasha, "Antibacterial Activity of Grapefruit (Citrus paradise) Peel Extracts," European Food Research Technology, Vol. 213, No. 6, 2001, pp. 484-487. doi:10.1007/s002170100394

[51] P. S. Negi, J. K. Saby and U. J. S. Prasada Rao, "Antimicrobial Activity of Mango Sap," European Food Research Technology, Vol. 214, No. 4, 2002, pp. 327-330. doi:10.1007/s00217-001-0485-7

[52] R. Scherrer and P. Gerhardt, "Molecular Sieving by the Bacillus megatrium Cell Wall and Protoplast" Journal of Bacteriology, Vol. 107, No. 3, 1971, pp. 718-735.

[53] H. Nikaido and M. Vaara, "Molecular Basis of Bacterial Outer Membrane Permeability," Microbiological Reviews, Vol. 49, No. 1, 1985, pp. 1-32.

[54] I. K. Sawer, M. I. Berry and J. L. Ford, "Effect of Medium Composition, Agitation and Presence of EDTA on the Antimicrobial Activity of Cryptolepine," Letters in Applied Microbiology, Vol. 25, No. 3, 1997, pp. 207-211. doi:10.1046/j.1472-765X.1997.00206.X

[55] Y. Gao, M. J. V. Belkum and M. Stiles, "The Outer Membrane of Gram-Negative Bacteria Inhibits Antibacterial Activity of Brochocin C," Applied Environmental Microbiology, Vol. 65, No. 10, 1999, pp. 4329-4333. 